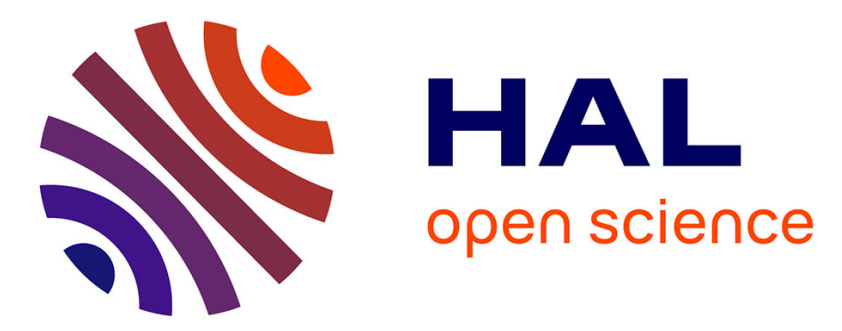

\title{
Subclinical left ventricular systolic impairment in steady state young adult patients with sickle-cell anemia
}

\author{
Nadjib Hammoudi, Dimitri Arangalage, Morad Djebbar, Katia Stankovic
}

Stojanovic, Magali Charbonnier, Richard Isnard, Robert Girot, Pierre-Louis

Michel, François Lionnet

\section{To cite this version:}

Nadjib Hammoudi, Dimitri Arangalage, Morad Djebbar, Katia Stankovic Stojanovic, Magali Charbonnier, et al.. Subclinical left ventricular systolic impairment in steady state young adult patients with sickle-cell anemia. International Journal of Cardiovascular Imaging, 2014, 30 (7), pp.1297-1304. 10.1007/s10554-014-0473-1 . hal-01103162

\section{HAL Id: hal-01103162 \\ https: / hal.sorbonne-universite.fr/hal-01103162}

Submitted on 14 Jan 2015

HAL is a multi-disciplinary open access archive for the deposit and dissemination of scientific research documents, whether they are published or not. The documents may come from teaching and research institutions in France or abroad, or from public or private research centers.
L'archive ouverte pluridisciplinaire HAL, est destinée au dépôt et à la diffusion de documents scientifiques de niveau recherche, publiés ou non, émanant des établissements d'enseignement et de recherche français ou étrangers, des laboratoires publics ou privés. 


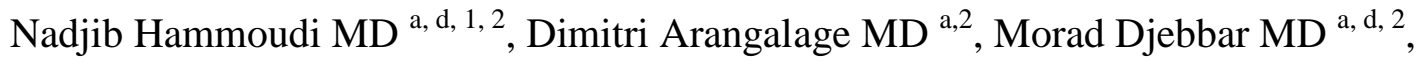

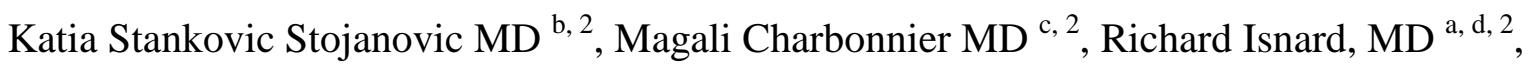
Robert Girot MD ${ }^{\text {b, d, } 2}$, Pierre-Louis Michel MD ${ }^{\text {a, d, } 2}$, François Lionnet MD b, d, 2

a Department of Cardiology, Assistance Publique - Hôpitaux de Paris, Pitié-Salpêtrière

9 Hospital, Paris, France ${ }^{b}$ Department of Internal Medicine, Reference Center for Adult Sicklecell Disease, Assistance Publique - Hôpitaux de Paris, Tenon Hospital, Paris, France ${ }^{\mathrm{c}}$

11 Department of Cardiology, Assistance Publique - Hôpitaux de Paris, Saint Antoine Hospital, Paris, France ${ }^{\mathrm{d}}$ University Paris 6, Faculté de Médecine Pierre et Marie Curie, Paris, France ${ }^{1}$ This author takes responsibility for all aspects of the reliability and freedom from bias of the data presented and their discussed interpretation ${ }^{2}$ This author drafted the article, revised it and provided the final approval of the version to be published.

16

Short title: Systolic impairment in sickle-cell anemia

Corresponding author: Nadjib Hammoudi, Institut de Cardiologie, Groupe Hospitalier

Pitié-Salpêtrière, Assistance Publique - Hôpitaux de Paris, 47-83, boulevard de l'Hôpital,

2175651 Paris Cedex 13. E-mail: nadjib.hammoudi@psl.aphp.fr. Telephone number: $22+33142165535$. Fax number: +33142163020. 


\section{ABSTRACT}

2 Purpose: Chronic volume overload in sickle-cell anemia (SCA) is associated with left

3 ventricular (LV) enlargement and hypertrophy. The effect of the disease on LV systolic

4 function remains debated. The aim of our study was to investigate LV systolic function in

$5 \quad$ SCA patients using 2D speckle-tracking imaging.

6 Methods: We compared 30 steady state asymptomatic adult SCA patients (17 women, mean 7 age $24.7 \pm 5.1$ years) with 30 age and sex-matched healthy subjects (17 women, mean age $825.0 \pm 4.9$ years). In addition to conventional echocardiographic parameters including LV 9 ejection fraction (EF) and LV mass index (LVMi), global longitudinal strain (GLS) and strain rate (GLSR) were measured.

11 Results: GLS (-17.9 $\pm 2.0 \%$ vs. $-19.7 \pm 2.5 \%, \mathrm{p}=0.004)$ and GLSR $\left(-0.92 \pm 0.09 \mathrm{~s}^{-1}\right.$ vs. $\left.121.07 \pm 0.17 \mathrm{~s}^{-1}, \mathrm{p}<0.0001\right)$ values were lower in SCA patients while LVEF values $(60.1 \pm 3.8 \%$ vs. $61.7 \pm 4.7 \%, \mathrm{p}=0.30$ ) were not different. LVMi was increased in SCA patients $\left(100.7 \pm 23.5 \mathrm{~g} / \mathrm{m}^{2}\right.$ vs. $\left.72.4 \pm 15.2 \mathrm{~g} / \mathrm{m}^{2}, \mathrm{p} 0.0001\right)$ and GLSR was significantly lower in the subgroup of patients with LV hypertrophy $\left(-0.88 \pm 0.09 \mathrm{~s}^{-1}\right.$ vs. $\left.-0.96 \pm 0.08 \mathrm{~s}^{-1}, \mathrm{p}=0.02\right)$. In SCA patients LVMi was correlated to GLS ( $\mathrm{r}=0.58, \mathrm{p}=0.001)$ and GLSR $(\mathrm{r}=0.45, \mathrm{p}=0.015)$

17 pleading in favor of a pathological LV remodeling.

Conclusions: Asymptomatic SCA patients exhibited a subclinical alteration of LV systolic function. Myocardial dysfunction appears to be linked to the degree of LV hypertrophy. 2D speckle-tracking imaging might be useful for long-term follow-up and to study the natural course of LV dysfunction in SCA patients.

Keywords: echocardiography, left ventricular function, speckle-tracking, strain, Sickle-cell anemia 


\section{BACKGROUND}

2 Sickle-cell disease is one of the most common inherited blood disorders worldwide [1].

3 Besides chronic anemia, many pathophysiological processes contribute to the complexity of

4 the disease including hemolysis and repeated vaso-occlusive events with ischemia-reperfusion

5 injury leading to endothelial cell dysfunction [1,2]. Concomitantly to the life expectancy

6 improvement observed over the past years, the prevalence of heart disease in adult patients

7 has also increased representing now up to one fourth of all deaths [3].

8 In patients with homozygous sickle cell disease, also called sickle-cell anemia (SCA), a

9 diastolic dysfunction, as well as left ventricular (LV) remodelling, including dilation and

10 hypertrophy, have been previously described [4]. These modifications are best explained by

11 an adaptative response to the volume overload effect of chronic anemia $[5,6]$.

12 While chronic volume overload in valvular heart disease such as mitral or aortic regurgitation

13 [7] and prolonged anemia induced by iron deficiency in rat models [8] induce LV systolic

14 dysfunction, its' occurrence in SCA disease is still debated with conflicting results in past studies [5, 6, 9-12]. Recently, ultrasound speckle-tracking imaging has emerged as a strong

16 and sensible tool that allows early diagnosis of LV systolic dysfunction [13].

17 We hypothesized that a systolic LV dysfunction that could be diagnosed by speckle-tracking imaging may exist during steady-state SCA disease in adult patients.

\section{METHODS}

\section{Study population}

22 We enrolled 30 patients with SCA, aged 18 years and older, in stable condition and in sinus rhythm. All these patients were referred to our echocardiography laboratory for routine outpatient evaluation of cardiac function and/or systematic screening for pulmonary arterial hypertension. The diagnosis of homozygous sickle-cell disease was based on molecular 
1 genetic techniques. Patients who had developed acute chest syndrome, vaso-occlusive crisis

2 or an acute complication within the previous 4 months, including fever, surgery, blood

3 transfusion or hospital admission whatever the reason, were excluded in order to specifically

4 focus on a group of steady state patients free of confounding factors that could be linked to an

5 impaired LV function. The other exclusion criteria were the use of cardiovascular medication

6 at the time of enrollment, hypertension, history of heart failure, moderate or severe valvular

7 heart disease, atrial fibrillation, pregnancy and the presence of an associated comorbidity

8 including autoimmune diseases, $\mathrm{HCV}$ or HIV infections and kidney failure defined by a

9 glomerular filtration rate $<60 \mathrm{ml} / \mathrm{mn} / 1.73 \mathrm{~m}^{2}$. Clinical and biological data were collected from

10 records of the reference centre for sickle-cell disease (Tenon Hospital, Paris, France). From

11 the general population, 30 age- and sex-matched healthy subjects without history of cardiac or

12 pulmonary disease and with normal electrocardiograms were recruited as control subjects.

13 Blood pressure was measured in patients and controls in supine position at the end of the

14 echocardiographic examination using a Dash 3000 monitor (GE Healthcare; Horten, Norway).

15 Informed consent was obtained from each patient. The study was approved by the institutional

16 committee on human research.

\section{Standard echocardiography}

19 Transthoracic echocardiography was performed in all patients with the use of the Vivid 7

20 system (GE Healthcare; Horten, Norway) and transferred to a workstation equipped with the

21 Echopac PC software (GE Vingmed Ultrasound; Horten, Norway) for offline analysis. All

22 exams were acquired and analyzed off-line blinded to the clinical data by a senior cardiologist

$23(\mathrm{NH})$. All measurements were averaged over 3 consecutive cardiac cycles. All projections

24 were obtained according to the recommendations of the American Society of

25 Echocardiography [14, 15]. From M-mode, the following measurements were made at end 
1 diastole: LV internal diameter, inter-ventricular septal and posterior wall thicknesses. LV

2 mass was derived and indexed to body surface area (LVMi), relative wall thickness was also

3 calculated (posterior wall thicknesses $\times 2$ / LV internal diameter) and LV remodeling was

4 categorized as recommended [15]. LV hypertrophy was defined by an LVMi $>95 \mathrm{~g} / \mathrm{m}^{2}$ in

5 women and $>115 \mathrm{~g} / \mathrm{m}^{2}$ in men. Further classification as either concentric hypertrophy (relative

6 wall thickness $>0.42$ ) or eccentric hypertrophy (relative wall thickness $\leq 0.42$ ) was made.

7 From 2-dimensional mode, end systolic left and right atrial areas were measured, LV volumes 8 and ejection fraction (LVEF) were derived from Simpson's modified biplane method. From

9 pulsed wave Doppler mode, LV outflow tract time-velocity integral, early and late peak 10 diastolic velocities of the mitral ( $\mathrm{E}$ and $\mathrm{A}$ ) inflow and the E-wave deceleration time were 11 measured. LV ejection volume and output were calculated and indexed to body surface area 12 as recommended [14]. The peak e' velocity was used to calculate the E/e' ratio using pulsed 13 tissue Doppler imaging of the lateral mitral annulus [16]. Diastolic dysfunction was defined 14 by E/A ratio $<1.0$ and/or a deceleration time $>240 \mathrm{~ms}$; E/A ratio $\geq 1.0$ and $\mathrm{E} / \mathrm{e}$ 'ratio $>10$; E/A 15 ratio higher than the $95^{\text {th }}$ percentile for age or deceleration time $<140 \mathrm{~ms}$ and $\mathrm{E} / \mathrm{e}^{\mathrm{\prime}}>10$. This 16 classification of LV diastolic function has a prognostic value on mortality in patients with 17 SCA [17].

18 From continuous wave Doppler, peak tricuspid regurgitation was recorded in multiple views 19 and the highest level of velocity was selected. Elevated pulmonary systolic pressure was 20 defined by a peak tricuspid regurgitation jet velocity $\geq 2.5 \mathrm{~m} / \mathrm{s}$, severe elevation by a peak 21 tricuspid regurgitation jet velocity $\geq 2.9 \mathrm{~m} / \mathrm{s}[18]$.

\section{Speckle-tracking imaging}

24 For 2D speckle-tracking imaging, sector size and depth were adjusted to achieve optimal 25 visualization of all LV myocardium at the highest possible frame rate (mean value $87 \pm 14$ 
1 frames/s). Multiple consecutive cardiac cycles of the 3 standard apical views $(4,2$ and 3

2 chambers views) were acquired during breath holding. In each view, the myocardium was

3 automatically divided by the software into 6 segments. The analyzed values within the middle

4 points for all resulting 18 segments were averaged to obtain the global longitudinal strain

5 (GLS) and the global longitudinal peak systolic strain rate (GLSR); in accordance with

6 current conventions GLS and GLSR values were presented as negative (segment shortening)

7 [13]. The adequacy of tracking was verified manually, and the region of interest was 8 readjusted to achieve optimal tracking. The segment was excluded if no acceptable border 9 was traced. GLS and GLSR values were not calculated if > 1 segment per view were 10 excluded.

\section{Statistical analysis}

13 All quantitative data are expressed as mean \pm standard deviation (SD); qualitative data are 14 expressed as number and as percentage. For case-control analysis, the Wilcoxon signed rank test was used for univariate analysis of continuous variables and the McNemar's test was used to compare categorical data.

17 Using the Mann-Whitney $U$ test and the chi-square test a secondary analysis compared the subgroup of patients with and without LV hypertrophy. The Pearson's correlation test was used to assess the univariate relations between variables.

Intraobserver and interobserver variabilities for LV deformation parameters, LV volume,

21 LVEF and LVMi measurements were assessed in 20 studies by 2 independent observers (NH 22 and DA). Using the Bland-Altman approach, the 95\% limit of agreement was calculated. In 23 addition, the coefficient of variation (CV) defined as the ratio of the SD of the difference of 24 paired samples to the average of the paired samples and the intra-class correlation coefficient 25 (ICC) were calculated. For intraobserver variability the CV and the ICC were respectively 
$14.1 \%$ and 0.93 for GLS, $4.3 \%$ and 0.92 for GLSR, $8.1 \%$ and 0.96 for LV end diastolic volume

2 index, $4 \%$ and 0.83 for LVEF and $5.5 \%$ and 0.99 for LVMi. The $95 \%$ limits of agreement 3 were -1.63 to $2.35 \%$ for GLS, -0.10 to 0.13 for GLSR, -17.1 to $14.7 \mathrm{ml} / \mathrm{m}^{2}$ for LV end

4 diastolic volume index, -7.1 to $6.8 \%$ for $\mathrm{LVEF}$ and -15.4 to $12.2 \mathrm{~g} / \mathrm{m}^{2}$ for LVMi. For 5 interobserver variability the CV and the ICC were respectively $6.6 \%$ and 0.88 for GLS, $6.2 \%$ 6 and 0.91 for GLSR, $7.6 \%$ and 0.96 for LV end diastolic volume index, $3.6 \%$ and 0.85 for 7 LVEF and $7.8 \%$ and 0.98 for LVMi. The $95 \%$ limits of agreement were -1.2 to $3.7 \%$ for GLS, -0.05 to 0.18 for GLSR, -11.0 to $16.5 \mathrm{ml} / \mathrm{m}^{2}$ for $\mathrm{LV}$ end diastolic volume index, -5.5 to $6.8 \%$ for LVEF and -15.1 to $21.7 \mathrm{~g} / \mathrm{m}^{2}$ for LVMi.

SPSS software version 17.0 (SPSS, Inc, Chicago, IL) was used for calculation. A p $<0.05$

11 indicated statistical significance.

RESULTS

14 Patients' mean age was $24.7 \pm 5.1$ years and 17 patients $(57 \%)$ out of a total of 30 were women. Percentages of patients with histories of thoracic vaso-occlusive events or cerebral 16 vasculopathy were $30 \%$ and $7 \%$ respectively. The mean hemoglobin level was $8.5 \pm 0.9 \mathrm{~g} / \mathrm{dl}$ and in 11 cases $(36 \%)$ it was $\leq 8 \mathrm{~g} / \mathrm{dl}$. Patients and controls were matched for age and gender and there was no significant difference between the 2 groups for body surface area and body mass index. Diastolic and mean blood pressures were significantly lower in patients than in controls; the heart rate was not higher in patients (Table 1), only 3 patients had heart rates >

$2190 / \mathrm{min}$ and none $>100 / \mathrm{min}$.

22 Morphological and hemodynamic characteristics are summarized in Table 2. LV dimensions and mass were greater in patients than in controls. In patients, the LV hypertrophy was mainly eccentric; only 1 patient had concentric hypertrophy. The mean tricuspid regurgitant jet 
1 velocity was higher in the patient group including 13 patients (43\%) with elevated pulmonary

2 systolic pressures and none with severe elevation.

3 LVEF measurements were $>50 \%$ in all patients. Despite similar LVEF between the 2 groups,

4 the GLS and the GLSR values were significantly decreased in the SCA group (Table 2, Figure

5 1). LV speckle analysis was not feasible in 1 patient and 1 control subject, because of poor 6 image quality. Patients presented a diastolic dysfunction and had a higher E/e' ratio (Table 2).

7 In order to assess the potential impact of blood pressure or heart rate on the relationship 8 between GLS and SCA, 3 linear regression analyses including respectively, mean arterial 9 blood pressure, diastolic blood pressure and heart rate were done. The results of the 3 analyses were similar and confirmed the independent link between GLS and SCA $\left(r^{2}=0.15, p=0.002\right)$.

11 The GLSR was significantly lower in patients with LV hypertrophy (Table 3). A correlation 12 was found between LVMi and GLS ( $\mathrm{r}=0.58, \mathrm{p}=0.001)$ as well as with GLSR ( $\mathrm{r}=0.45$, $\mathrm{p}=0.015$ ). There was a significant inverse correlation between the hemoglobin level and LVMi ( $\mathrm{r}=-0.43, \mathrm{p}=0.017)$ as well as LV end-diastolic diameter index $(\mathrm{r}=-0.36, \mathrm{p}=0.047)$. The hemoglobin level was not statistically correlated to LVEF ( $r=-0.04, \mathrm{p}=0.83)$, E/e' ratio $(\mathrm{r}=-$ $0.28, \mathrm{p}=0.13), \operatorname{GLS}(\mathrm{r}=0.15, \mathrm{p}=0.44)$ and $\operatorname{GLSR}(\mathrm{r}=0.28, \mathrm{p}=0.14)$.

\section{DISCUSSION}

In this study we found that in addition to morphological modifications including hypertrophy and dilation, LV systolic function assessed by 2D speckle tracking imaging was impaired in a

21 population of steady state SCA young asymptomatic adult patients with preserved LVEF. The 22 severity of LV hypertrophy was linked to the impairment of global longitudinal LV deformation parameters. The GLS was linked to SCA independently to blood pressure and to heart rate. LV remodeling was inversely associated to the hemoglobin level. 
1 Despite not being a pure form of anemia [19], the LV remodeling observed in homozygous

2 sickle-cell disease is commonly attributed to chronic anemia as reduced blood oxygen3 carrying capacity induces an increased cardiac output [4]. As described in this study and noted

4 previously by others, an important stroke volume increase associated with a relatively mild

5 heart rate elevation contribute to the cardiac output increase [12]. Modifications in LV

6 preload and afterload could explain the stroke volume increase; the significant reduction of

7 the mean arterial blood pressure while the cardiac index is increased underlines the decrease 8 in peripheral vascular resistances [20]. Volume overload contributes to the increased cardiac

9 output by inducing an increase in LV preload and a substantial LV enlargement[21, 22].

10 According to Laplace's Law, this volume overload increases the peak systolic wall stress

11 resulting in wall thickening to normalize the systolic stress. Wall thickening and fiber

12 elongation contribute to the pattern of eccentric hypertrophy in which the ratio of wall 13 thickness to chamber radius remains normal [23].

14 Regarding the LV systolic function assessment, conflicting results in previous studies are 15 partly explained by the multitude of different echocardiographic parameters used to assess 16 myocardial contractility including load-dependant measures such as the LVEF calculation [6, 17 12, 24-26]. In our study, deformation parameters were significantly reduced while the LVEF was similar in both groups. Myocardial deformation assessed by strain and strain-rate is the result of a complex interaction between the intrinsic contractile force and the extrinsic loading conditions applied to a tissue with variable elastic properties [27]. Therefore, it could be 21 argued that the observed modifications of LV longitudinal deformation may not only be the 22 result of an alteration in contractility but may reflect modifications of loading conditions or in myocardial stiffness. In our study the afterload was lower and the preload higher in the SCA

24 group and it is admitted that under these conditions deformation values should increase [28, 25 29]. This argument pleads in favor of the occurrence of a LV systolic impairment in young 
1 adult SCA patients. Similarly, a recent meta-analysis reported an impairment of a relatively

2 load independent LV systolic function assessment parameter (end-systolic stress to end-

3 systolic volume index) despite preservation of load dependant parameters in SCA patients

$4[30]$.

5 An interesting parallel can be made concerning LV remodeling between patients suffering

6 from chronic anemia and endurance athletes in whom a comparable cardiac remodeling has

7 been reported [31]. In contrast with the results of our study, LV strain and strain rate values in

8 endurance athletes have been reported to be normal or increased [32, 33]. Besides, while

9 increased LV mass is associated with improved deformation indices in endurance athletes

10 [32], LV hypertrophy is associated with an impairment of LV function in our population

11 further supporting the hypothesis that a LV myocardial impairment exists in sickle-cell

12 disease patients. Similar findings have been reported in the course of hypertrophic cardiomyopathy [32] and myocardial fibrosis is associated with depressed strain values in

14 these patients [34]. Moreover, as morphological and functional LV parameters are linked, LV 15 mass may be helpful in routine practice for the identification of a subgroup of SCA patients 16 athigh risk of LV dysfunction.

17 In case of severe organic mitral regurgitation, prolonged burden due to volume overload might result in LV dysfunction and irreversible myocardial damage. If a significant LV myocardial morphological and/or functional involvement is/are identified, current guidelines recommend the correction of the regurgitation in asymptomatic patients [7]. The LV 21 abnormalities observed in SCA patients are multifactorial including the combination of 22 chronic anemia and microvascular dysfunction[4]. In our study, LV deformation parameters revealed a LV impairment in a population of young adult SCA patients with normal LVEF,

24 suggesting a promising role of these parameters for the detection of LV dysfunction at an 25 early stage before major and irreversible damage of the myocardium occurs. As 
1 cardiovascular mortality in adult SCA patients is high[3] our findings may provide clinicians

2 a useful method of identification of a category of patients at high risk of developing long-

3 term congestive heart failure and/or premature death. Moreover these patients may benefit

4 from more regular follow up and more aggressive clinical interventions in order to improve

5 their prognosis.

6 A similar study using deformation imaging was recently conducted on a pediatric population

7 of sickle cell disease patients with contrasting results as deformation indices were not 8 modified [35]. It could be hypothesized that the LV systolic impairment, as found in our

9 population of adults, occurs later in the course of the disease. Age related deterioration of LV 10 systolic function was previously described [30]. Moreover, in a population of adult patients 11 presenting with sickle-cell crisis, the usefulness of deformation indices assessed by speckle 12 tracking for detecting LV systolic function impairment has already been reported [36]; our 13 study identified LV dysfunction in a population of steady-state patients. Contrastingly, no 14 impairment in LV systolic function was reported in a study based on 3-dimensional LV 15 speckle tracking echocardiography [37]. This promising new method performed on a pre16 commercial prototype software still suffers from technical limitations such as low temporal 17 resolution. Besides, in addition to SCA patients, hemoglobin sickle-cell (SC) patients were 18 also included in this study. It has already been described that SC patients have very different 19 clinical and biological characteristics [38]. Therefore, the results must be compared to ours 20 with caution.

21 Consistently with previous studies [10, 17, 39, 40], we also found a LV diastolic function 22 impairment. Diastolic dysfunction is known to be an independent risk factor for mortality in 23 SCA [17]. It is worth noting that the E/e' ratio is normal in healthy endurance athletes [32, 24 33]. 
1 Several limitations of our study need to be acknowledged. First, our population was relatively

2 small as we decided to focus on strict inclusion criteria in order to reduce any bias by

3 selecting only steady state homozygous sickle-cell disease patients free of confounding

4 factors that could be linked to LV systolic impairment. Despite this limitation, we found a

5 significant impairment of deformation indices. Second, we only evaluated the LV longitudinal

6 deformation parameters as they appear to be the most efficient and reproducible parameters in

7 speckle tracking technology [41]. Moreover, it has been earlier described that the natural

8 course of myocardial diseases is characterized by the impairment of the longitudinal function

9 that occurs before the onset of circumferential and radial alterations [42]. Finally, the

10 prognostic implications of LV deformation parameters were not assessed in this study and

11 need further investigations.

12 Steady state young adult patients suffering from homozygous sickle-cell anemia exhibited a

13 subclinical impairment of myocardial contractility. 2D speckle-tracking imaging might

14 constitute a useful tool for long-term follow-up and to study the natural course of LV

15 dysfunction in these patients. Additional studies are required to further understand the 16 prognostic implications of deformation parameters.

17 


\section{DISCLOSURES}

2 The authors have no disclosures.

3

4 FUNDING, GRANT OR OTHER SUPPORT

5 None

6

\section{ACKNOWLEDGEMENT}

$8 \quad$ None

9

10

11

12

13

14

15

16

17

18

19

20

21

22

23

24

25 


\section{REFERENCES}

1. Weatherall D, Hofman K, Rodgers G, et al. (2005) A case for developing North-South partnerships for research in sickle cell disease. Blood 105:921-923. doi: 10.1182/blood-2004-06-2404

2. Rees DC, Williams TN, Gladwin MT (2010) Sickle-cell disease. Lancet 376:2018-2031. doi: 10.1016/S0140-6736(10)61029-X

3. Fitzhugh CD, Lauder N, Jonassaint JC, et al. (2010) Cardiopulmonary complications leading to premature deaths in adult patients with sickle cell disease. Am J Hematol 85:36-40. doi: 10.1002/ajh.21569

4. Gladwin MT, Sachdev V (2012) Cardiovascular abnormalities in sickle cell disease. J Am Coll Cardiol 59:1123-1133. doi: 10.1016/j.jacc.2011.10.900

5. Batra AS, Acherman RJ, Wong W, et al. (2002) Cardiac abnormalities in children with sickle cell anemia. Am J Hematol 70:306-312. doi: 10.1002/ajh.10154

6. Lester LA, Sodt PC, Hutcheon N, Arcilla RA (1990) Cardiac abnormalities in children with sickle cell anemia. Chest 98:1169-1174.

7. Vahanian A, Alfieri O, Andreotti F, et al. (2012) Guidelines on the management of valvular heart disease (version 2012): the Joint Task Force on the Management of Valvular Heart Disease of the European Society of Cardiology (ESC) and the European Association for Cardio-Thoracic Surgery (EACTS). Eur J Cardio-Thorac Surg Off J Eur Assoc Cardio-Thorac Surg 42:S1-44. doi: 10.1093/ejcts/ezs455

8. Naito Y, Tsujino T, Matsumoto M, et al. (2009) Adaptive response of the heart to longterm anemia induced by iron deficiency. Am J Physiol Heart Circ Physiol 296:H585593. doi: 10.1152/ajpheart.00463.2008

9. Voskaridou E, Christoulas D, Terpos E (2012) Sickle-cell disease and the heart: review of the current literature. $\mathrm{Br} \mathrm{J}$ Haematol 157:664-673. doi: 10.1111/j.13652141.2012.09143.x

10. Eddine AC, Alvarez O, Lipshultz SE, et al. (2012) Ventricular structure and function in children with sickle cell disease using conventional and tissue Doppler echocardiography. Am J Cardiol 109:1358-1364. doi: 10.1016/j.amjcard.2012.01.001

11. Lamers L, Ensing G, Pignatelli R, et al. (2006) Evaluation of left ventricular systolic function in pediatric sickle cell anemia patients using the end-systolic wall stressvelocity of circumferential fiber shortening relationship. J Am Coll Cardiol 47:22832288. doi: 10.1016/j.jacc.2006.03.005

12. Covitz W, Espeland M, Gallagher D, et al. (1995) The heart in sickle cell anemia. The Cooperative Study of Sickle Cell Disease (CSSCD). Chest 108:1214-1219. 
13. Mor-Avi V, Lang RM, Badano LP, et al. (2011) Current and evolving echocardiographic techniques for the quantitative evaluation of cardiac mechanics: ASE/EAE consensus statement on methodology and indications endorsed by the Japanese Society of Echocardiography. J Am Soc Echocardiogr Off Publ Am Soc Echocardiogr 24:277313. doi: 10.1016/j.echo.2011.01.015

14. Quiñones MA, Otto CM, Stoddard M, et al. (2002) Recommendations for quantification of Doppler echocardiography: a report from the Doppler Quantification Task Force of the Nomenclature and Standards Committee of the American Society of Echocardiography. J Am Soc Echocardiogr Off Publ Am Soc Echocardiogr 15:167184.

15. Lang RM, Bierig M, Devereux RB, et al. (2005) Recommendations for chamber quantification: a report from the American Society of Echocardiography's Guidelines and Standards Committee and the Chamber Quantification Writing Group, developed in conjunction with the European Association of Echocardiography, a branch of the European Society of Cardiology. J Am Soc Echocardiogr Off Publ Am Soc Echocardiogr 18:1440-1463. doi: 10.1016/j.echo.2005.10.005

16. Nagueh SF, Appleton CP, Gillebert TC, et al. (2009) Recommendations for the evaluation of left ventricular diastolic function by echocardiography. J Am Soc Echocardiogr Off Publ Am Soc Echocardiogr 22:107-133. doi: 10.1016/j.echo.2008.11.023

17. Sachdev V, Machado RF, Shizukuda Y, et al. (2007) Diastolic dysfunction is an independent risk factor for death in patients with sickle cell disease. J Am Coll Cardiol 49:472-479. doi: 10.1016/j.jacc.2006.09.038

18. Parent F, Bachir D, Inamo J, et al. (2011) A hemodynamic study of pulmonary hypertension in sickle cell disease. $\mathrm{N}$ Engl J Med 365:44-53. doi: 10.1056/NEJMoa1005565

19. Sun K, Xia Y (2013) New insights into sickle cell disease: a disease of hypoxia. Curr Opin Hematol 20:215-221. doi: 10.1097/MOH.0b013e32835f55f9

20. Denenberg BS, Criner G, Jones R, Spann JF (1983) Cardiac function in sickle cell anemia. Am J Cardiol 51:1674-1678.

21. Varat MA, Adolph RJ, Fowler NO (1972) Cardiovascular effects of anemia. Am Heart J 83:415-426.

22. Takahashi M, Kurokawa S, Tsuyusaki T, Kikawada R (1990) [Studies of hyperkinetic circulatory state in chronic anemia]. J Cardiol 20:331-339.

23. Grossman W, Jones D, McLaurin LP (1975) Wall stress and patterns of hypertrophy in the human left ventricle. J Clin Invest 56:56-64. doi: 10.1172/JCI108079

24. Balfour IC, Covitz W, Davis H, et al. (1984) Cardiac size and function in children with sickle cell anemia. Am Heart J 108:345-350.

25. Covarrubias EA, Sheikh MU, Solanki DL, et al. (1980) Left ventricular function in sickle cell anemia: a noninvasive evaluation. South Med J 73:342-344. 
26. Gerry JL, Baird MG, Fortuin NJ (1976) Evaluation of left ventricular function in patients with sickle cell anemia. Am J Med 60:968-972.

27. Sutherland GR, Di Salvo G, Claus P, et al. (2004) Strain and strain rate imaging: a new clinical approach to quantifying regional myocardial function. J Am Soc Echocardiogr Off Publ Am Soc Echocardiogr 17:788-802. doi: 10.1016/j.echo.2004.03.027

28. Burns AT, La Gerche A, D'hooge J, et al. (2010) Left ventricular strain and strain rate: characterization of the effect of load in human subjects. Eur $\mathrm{J}$ Echocardiogr $\mathrm{J}$ Work Group Echocardiogr Eur Soc Cardiol 11:283-289. doi: 10.1093/ejechocard/jep214

29. Rösner A, Bijnens B, Hansen M, et al. (2009) Left ventricular size determines tissue Doppler-derived longitudinal strain and strain rate. Eur J Echocardiogr J Work Group Echocardiogr Eur Soc Cardiol 10:271-277. doi: 10.1093/ejechocard/jen230

30. Poludasu S, Ramkissoon K, Salciccioli L, et al. (2013) Left ventricular systolic function in sickle cell anemia: a meta-analysis. J Card Fail 19:333-341. doi: 10.1016/j.cardfail.2013.03.009

31. Pelliccia A, Maron MS, Maron BJ (2012) Assessment of left ventricular hypertrophy in a trained athlete: differential diagnosis of physiologic athlete's heart from pathologic hypertrophy. Prog Cardiovasc Dis 54:387-396. doi: 10.1016/j.pcad.2012.01.003

32. Galderisi M, Lomoriello VS, Santoro A, et al. (2010) Differences of myocardial systolic deformation and correlates of diastolic function in competitive rowers and young hypertensives: a speckle-tracking echocardiography study. J Am Soc Echocardiogr Off Publ Am Soc Echocardiogr 23:1190-1198. doi: 10.1016/j.echo.2010.07.010

33. Baggish AL, Yared K, Wang F, et al. (2008) The impact of endurance exercise training on left ventricular systolic mechanics. Am J Physiol Heart Circ Physiol 295:H1109H1116. doi: 10.1152/ajpheart.00395.2008

34. Popović ZB, Kwon DH, Mishra M, et al. (2008) Association between regional ventricular function and myocardial fibrosis in hypertrophic cardiomyopathy assessed by speckle tracking echocardiography and delayed hyperenhancement magnetic resonance imaging. J Am Soc Echocardiogr Off Publ Am Soc Echocardiogr 21:1299-1305. doi: 10.1016/j.echo.2008.09.011

35. Blanc J, Stos B, de Montalembert M, et al. (2012) Right ventricular systolic strain is altered in children with sickle cell disease. J Am Soc Echocardiogr Off Publ Am Soc Echocardiogr 25:511-517. doi: 10.1016/j.echo.2012.01.011

36. Sengupta SP, Jaju R, Nugurwar A, et al. (2012) Left ventricular myocardial performance assessed by 2-dimensional speckle tracking echocardiography in patients with sickle cell crisis. Indian Heart J 64:553-558. doi: 10.1016/j.ihj.2012.07.021

37. Ahmad H, Gayat E, Yodwut C, et al. (2012) Evaluation of myocardial deformation in patients with sickle cell disease and preserved ejection fraction using threedimensional speckle tracking echocardiography. Echocardiogr Mt Kisco N 29:962969. doi: 10.1111/j.1540-8175.2012.01710.x 


\section{8}

38. Lionnet F, Hammoudi N, Stojanovic KS, et al. (2012) Hemoglobin sickle cell disease complications: a clinical study of 179 cases. Haematologica 97:1136-1141. doi: 10.3324/haematol.2011.055202

39. Caldas MC, Meira ZA, Barbosa MM (2008) Evaluation of 107 patients with sickle cell anemia through tissue Doppler and myocardial performance index. J Am Soc Echocardiogr Off Publ Am Soc Echocardiogr 21:1163-1167. doi: 10.1016/j.echo.2007.06.001

40. Johnson MC, Kirkham FJ, Redline S, et al. (2010) Left ventricular hypertrophy and diastolic dysfunction in children with sickle cell disease are related to asleep and waking oxygen desaturation. Blood 116:16-21. doi: 10.1182/blood-2009-06-227447

41. Feigenbaum H, Mastouri R, Sawada S (2012) A practical approach to using strain echocardiography to evaluate the left ventricle. Circ J Off J Jpn Circ Soc 76:15501555 .

42. Kalogeropoulos AP, Georgiopoulou VV, Gheorghiade M, Butler J (2012) Echocardiographic evaluation of left ventricular structure and function: new modalities and potential applications in clinical trials. J Card Fail 18:159-172. doi: 10.1016/j.cardfail.2011.10.019 


\section{FIGURE LEGENDS}

2

3 Figure 1. Comparison of LV global longitudinal strain measures between a sickle-cell anemia

4 patient and an age and sex-matched control subject. Despite similar LV ejection fractions, LV

5 peak global longitudinal strain value (white curve; arrow) is significantly decreased in the

6 sickle-cell anemia patients' measure.

$7 \quad$ GLS $=$ Global longitudinal Strain $;$ LVEF $=$ Left ventricular ejection fraction; SCA = Sickle8 cell Anemia.

9

10

11

12

13

14

15

16

17

18

19

20

21

22

23

24

25 
1 Table 1: General characteristics of the study subjects

2

\begin{tabular}{|l|c|c|c|}
\hline & $\begin{array}{c}\text { SCA patients } \\
(\mathrm{n}=30)\end{array}$ & $\begin{array}{c}\text { Controls } \\
(\mathrm{n}=30)\end{array}$ & p value \\
\hline Age (years) & $24.7 \pm 5.1$ & $25.0 \pm 4.9$ & 0.08 \\
\hline Women & $17(57)$ & $17(57)$ & matched \\
\hline Body Mass index $\left(\mathrm{g} / \mathrm{m}^{2}\right)$ & $21.0 \pm 3.2$ & $22.0 \pm 2.9$ & 0.23 \\
\hline Body surface area $\left(\mathrm{m}^{2}\right)$ & $1.75 \pm 0.18$ & $1.78 \pm 0.19$ & 0.26 \\
\hline Systolic Blood Pressure (mmHg) & $114.2 \pm 9.3$ & $119.0 \pm 11.1$ & 0.11 \\
\hline Diastolic Blood Pressure $(\mathrm{mmHg})$ & $65.5 \pm 8.6$ & $70.8 \pm 7.0$ & 0.008 \\
\hline Mean Blood Pressure $(\mathrm{mmHg})$ & $81.7 \pm 7.9$ & $86.9 \pm 7.4$ & 0.02 \\
\hline Heart rate (beats/min) & $72.5 \pm 10.3$ & $67.7 \pm 11.4$ & 0.07 \\
\hline
\end{tabular}

Data are expressed as mean \pm SD or as number $(\%)$

$4 \quad \mathrm{SCA}=$ Sickle Cell Anemia

5

6

7

8

9

10

11

12

13

14

15 
1 Table 2: Echocardiographic measurements in patients and controls

\begin{tabular}{|c|c|c|c|}
\hline & $\begin{array}{l}\text { SCA patients } \\
\quad(n=30)\end{array}$ & $\begin{array}{l}\text { Controls } \\
(n=30)\end{array}$ & $\mathrm{p}$ value \\
\hline LVEDD index $\left(\mathrm{mm} / \mathrm{m}^{2}\right)$ & $30.8 \pm 3.2$ & $28.3 \pm 2.1$ & 0.0009 \\
\hline LV mass index $\left(\mathrm{g} / \mathrm{m}^{2}\right)$ & $100.7 \pm 23.5$ & $72.4 \pm 15.2$ & 0.0001 \\
\hline LV mass index $\left(\mathrm{g} / \mathrm{m}^{2}\right)$ in women $(\mathrm{n}=17)$ & $98.6 \pm 19.2$ & $66.6 \pm 13.4$ & 0.0001 \\
\hline LV mass index $\left(\mathrm{g} / \mathrm{m}^{2}\right)$ in men $(\mathrm{n}=13)$ & $107.3 \pm 26.5$ & $80.0 \pm 14.6$ & 0.03 \\
\hline LV hypertrophy & $14(47)$ & $1(3)$ & $<0.0001$ \\
\hline LV eccentric hypertrophy & $13(43)$ & $1(3)$ & 0.0002 \\
\hline LVEDV index $\left(\mathrm{ml} / \mathrm{m}^{2}\right)$ & $80.9 \pm 16.0$ & $59.5 \pm 13.0$ & $<0.0001$ \\
\hline $\mathrm{LV}$ ejection volume index $\left(\mathrm{ml} / \mathrm{m}^{2}\right)$ & $56.4 \pm 9.6$ & $47.3 \pm 7.6$ & 0.0004 \\
\hline Cardiac index $\left(\mathrm{L} / \mathrm{min} / \mathrm{m}^{2}\right)$ & $4.1 \pm 0.7$ & $3.2 \pm 0.6$ & 0.0001 \\
\hline TR velocity $(\mathrm{m} / \mathrm{s})$ & $2.4 \pm 0.2$ & $2.1 \pm 0.2 *$ & $<0.0001$ \\
\hline TR velocity $>2.5 \mathrm{~m} / \mathrm{s} \mathrm{n,} \mathrm{\%}$ & $13(43.3)$ & $1(3.7)^{*}$ & 0.001 \\
\hline Left atrial area $\left(\mathrm{cm}^{2}\right)$ & $23.8 \pm 3.8$ & $18.0 \pm 3.9$ & $<0.0001$ \\
\hline Right atrial area $\left(\mathrm{cm}^{2}\right)$ & $17.7 \pm 2.9$ & $14.4 \pm 3.5$ & 0.0001 \\
\hline \multicolumn{4}{|l|}{ Diastolic function } \\
\hline $\mathrm{E}(\mathrm{cm} / \mathrm{s})$ & $94.6 \pm 16.0$ & $79.9 \pm 14.1$ & 0.0003 \\
\hline $\mathrm{A}(\mathrm{cm} / \mathrm{s})$ & $49.5 \pm 11.7$ & $46.2 \pm 11.0$ & 0.33 \\
\hline $\mathrm{E} / \mathrm{A}$ & $2.0 \pm 0.5$ & $1.8 \pm 0.4$ & 0.04 \\
\hline E-wave deceleration time (ms) & $169.5 \pm 34.6$ & $153.3 \pm 30.7$ & 0.02 \\
\hline $\mathrm{e}^{\prime}(\mathrm{cm} / \mathrm{s})$ & $17.4 \pm 3.7 * *$ & $19.0 \pm 3.5$ & 0.11 \\
\hline $\mathrm{E} / \mathrm{e}^{\prime}$ & $5.8 \pm 2.5 * *$ & $4.5 \pm 2.1$ & 0.0003 \\
\hline Diastolic dysfunction & $6(20)$ & $0(0)$ & 0.03 \\
\hline
\end{tabular}




\begin{tabular}{|l|c|c|c|}
\hline \multicolumn{2}{|l|}{ Systolic function } \\
\hline LVEF $(\%)$ & $60.1 \pm 3.8$ & $61.7 \pm 4.7$ & 0.30 \\
\hline Global longitudinal strain $(\%)$ & $-17.9 \pm 2.0 * *$ & $-19.7 \pm 2.5 * *$ & 0.004 \\
\hline Global longitudinal strain rate $\left(\mathrm{s}^{-1}\right)$ & $-0.92 \pm 0.09 * *$ & $-1.07 \pm 0.17 * *$ & $<0.0001$ \\
\hline$* \mathrm{n}=27, * * \mathrm{n}=29$ & & & \\
\hline
\end{tabular}

2 Data are expressed as mean $\pm \mathrm{SD}$ or as number $(\%)$

$3 \mathrm{~A}=$ Late peak diastolic velocity of the mitral inflow; $\mathrm{E}=$ Early peak diastolic velocity of the

4 mitral inflow; e' = early diastolic mitral annular tissue Doppler velocity, E/e' = ratio between

5 peak velocities of mitral $\mathrm{E}$ wave and early-diastolic mitral annulus; LVEDD = Left

6 ventricular end-diastolic diameter; $\mathrm{LVEDV}=$ Left ventricular end-diastolic volume; LVEF =

7 left ventricular ejection fraction; TR velocity = tricuspid regurgitant maximal velocity; SCA =

8 Sickle Cell Anemia

9

10

11

12

13

14

15

16

17

18

19

20

21 
1 Table 3: Comparison of clinical and echocardiographic data according to LV Mass index in

2 Sickle cell Anemia patients

\begin{tabular}{|c|c|c|c|}
\hline & $\begin{array}{c}\text { LV } \\
\text { hypertrophy } \\
(n=14)\end{array}$ & $\begin{array}{c}\text { Normal } \\
\text { LV morphology } \\
(n=16)\end{array}$ & $\mathrm{p}$ value \\
\hline Age (years) & $24.3 \pm 5.3$ & $25.0 \pm 5.1$ & 0.80 \\
\hline Women & $10(71)$ & $7(44)$ & 0.13 \\
\hline Systolic Blood Pressure (mmHg) & $114.4 \pm 10.0$ & $113.9 \pm 9.0$ & 0.88 \\
\hline Diastolic Blood Pressure (mmHg) & $64.1 \pm 7.8$ & $66.7 \pm 9.3$ & 0.51 \\
\hline Heart rate (beats/min) & $70.9 \pm 10.6$ & $73.9 \pm 10.1$ & 0.37 \\
\hline Hemoglobin $(\mathrm{g} / \mathrm{dl})$ & $8.3 \pm 0.6$ & $8.8 \pm 1.1$ & 0.21 \\
\hline LV mass index $\left(\mathrm{g} / \mathrm{m}^{2}\right)$ & $119.2 \pm 17.0$ & $84.6 \pm 14.8$ & $<0.0001$ \\
\hline Cardiac index $\left(\mathrm{L} / \mathrm{min} / \mathrm{m}^{2}\right)$ & $4.2 \pm 0.6$ & $3.9 \pm 0.8$ & 0.13 \\
\hline TR velocity $(\mathrm{m} / \mathrm{s})$ & $2.4 \pm 0.2$ & $2.4 \pm 0.2$ & 0.52 \\
\hline $\mathrm{E}(\mathrm{cm} / \mathrm{s})$ & $100.2 \pm 13.3$ & $89.6 \pm 17.0$ & 0.05 \\
\hline $\mathrm{A}(\mathrm{cm} / \mathrm{s})$ & $48.8 \pm 13.0$ & $50.1 \pm 10.7$ & 0.49 \\
\hline $\mathrm{E} / \mathrm{A}$ & $2.2 \pm 0.5$ & $1.9 \pm 0.4$ & 0.15 \\
\hline E-wave deceleration time (ms) & $163.6 \pm 21.9$ & $174.6 \pm 42.9$ & 0.65 \\
\hline $\mathrm{e}^{\prime}(\mathrm{cm} / \mathrm{s})$ & $16.6 \pm 4.0^{*}$ & $18.0 \pm 3.4$ & 0.38 \\
\hline E/e’ & $6.7 \pm 3.4^{*}$ & $5.1 \pm 1.3$ & 0.10 \\
\hline Diastolic dysfunction & $5(36)$ & $1(6)$ & 0.04 \\
\hline LV Ejection Fraction (\%) & $59.4 \pm 3.8$ & $60.8 \pm 3.8$ & 0.42 \\
\hline Global longitudinal strain (\%) & $-17.1 \pm 2.4^{*}$ & $-18.5 \pm 1.5$ & 0.07 \\
\hline Global longitudinal strain rate $\left(\mathrm{s}^{-1)}\right.$ & $-0.88 \pm 0.09^{*}$ & $-0.96 \pm 0.08$ & 0.02 \\
\hline
\end{tabular}


1 Data are expressed as mean $\pm \mathrm{SD}$ or as number $(\%)$

2 TR velocity $=$ tricuspid regurgitant maximal velocity; $\mathrm{E}=$ Early peak diastolic velocity of the 3 mitral inflow; $\mathrm{A}=$ Late peak diastolic velocity of the mitral inflow; e' = early diastolic mitral 4 annular tissue Doppler velocity, E/e' = ratio between peak velocities of mitral E wave and 5 early-diastolic mitral annulus; SCA = Sickle Cell Anemia

6

7 